\title{
Strategic Leadership and Employee Engagement, Evidences from an African Industrial Setting
}

\author{
Hannah Muzee1, Vincent Bagire², Muhammed Ngoma² \\ ${ }^{1}$ Institute of Governance, Humanities and Social Sciences, Pan African University, Yaounde, Cameroon \\ ${ }^{2}$ Makerere University Business School, Kampala, Uganda \\ Email: Muzhann2002@gmail.com,bagirev@yahoo.com,mngoma@mubs.ac.ug
}

Received 15 July 2016; accepted 25 August 2016; published 29 August 2016

Copyright (C) 2016 by authors and OALib.

This work is licensed under the Creative Commons Attribution International License (CC BY). http://creativecommons.org/licenses/by/4.0/

\section{(c) (i) Open Access}

\begin{abstract}
This study followed a cross-sectional and descriptive research design. The study aimed at establishing the relationship between strategic leadership and employee engagement. A simple random sampling design was employed to a sample obtained from one of the leading breweries in Uganda. The findings showed that strategic leadership was indeed evident in the organization. They also revealed that strategic leadership and employee engagement were significantly and positively correlated and that strategic leadership was significant predictor of employee engagement. It was therefore concluded that organizations should invest in training their managers in strategic leadership skills to improve on their relations with the subordinates.
\end{abstract}

\section{Keywords}

Strategic Leadership, Employee Engagement

Subject Areas: Human Resource Management

\section{Background}

The performance and wellbeing of employees in an organization is to an extent dependent on the type of leadership prevailing. The Upper Echelon Theory, one of the major antecedents of Strategic Leadership suggests that an organization is a reflection of the cognitions and values of its top lead [1]. Strategic leadership is centered on 6 components: strategic direction, ethical practices, exploitation and maintenance of core competences, development of human capital and sustaining of a corporate culture [1] [2]. Based on this Boal [1] suggested that the essence of strategic leadership is the creation and maintenance of absorptive capacity (capacity to learn), adaptive capacity (capacity to change) and Managerial wisdom (Discernment). Despite the fact that organizations be- 
lieve the human resource to be an asset to their effective performance, they have grappled with the problem of keeping them engaged. As more and more employees are looking for work environments that are fulfilling, and offer prospects for full engagement and self expression. Organizations are then put to task to not only embark on formulating a vision but also endeavor to ensure that organizational members work together to achieve viable change or risk losing their employees to their competitors. Once leaders exercise discernment in dealings with their subordinates then they are able to elicit collaborative behavior and more engagement levels.

For example Toni Fourie, the appointed CEO of Ellerine Holdings Ltd. after its acquisition by African Bank Investments Ltd., was able to reverse the company's declining financial position by sowing a new organizational culture; encouraging innovation and creative thinking, collaborative and participatory engagement. The case concluded that successful organizational transformation is dependent on strategic leaders, who are committed to the vision and are resilient to competitors in turbulent economic conditions [3]. The continued success of an organization is reflective of the leaders' decisions of its leaders [4]. For effective transformation to take place the leader needs to win the trust of his subordinates by exhibiting integrity in their dealings, showing concern and interest in subordinates goals and values [2] [5]. Once employees perceive fairness in the latter they are likely to reciprocate with collaborative behavior.

Employee engagement is referred to as the harnessing of organization members' selves to their work roles; in engagement people employ and express themselves physically, cognitively and emotionally during role performances [6]. Recent studies have related, job satisfaction, high organizational commitment and performance as positive outcomes of engagement [7] [8]. However many organizations are facing a challenge in keeping their employee engaged.

In Uganda, one of the leading breweries (Nile Breweries) established in 1951 by the Madhivani Group reported a commitment to treating employees with fairness and respect; however they still grappled with the issue of employee engagement evidenced by more than half (52\%) the population spending less than 3 years in the organization. Similarly in Ghana, Guinness Ghana Breweries reported a 16\% level of super engaged employees in 2007. It was attributed to employee perception of management as not making any deliberate attempt to properly and adequately improving engagement levels [9]. Building an engaged workforce is certainly a working progress; therefore this study attempted to examine the challenge faced by modern industries in trying to create an engaged workforce.

\subsection{Review of Related Literature}

\subsubsection{Perspectives of Strategic Leadership}

A number of perspectives attempt to explain strategic leadership. The upper echelon theory argues that organizations are a reflection of its leadership [1]. Borrowing from the latter the Strategic Leadership theory contends that organizations are reflection of experience, values, abilities, social connections, aspirations of its top executives [8]. It can therefore be assumed that strategic leadership attempts to offer an explanation for the behavior of strategic leaders while the upper echelon theory basically emphasizes the influence of leaders on the organization.

The positive agency theory too attempted to explain the action of leaders. It claimed that top executives mainly acted in their own interests as opposed to those of shareholders [10]. However, if subject to control systems then their interests would be related. While some scholars argue that it's a theory about strategic leaders some say it's more of a theory of corporate governance [1].

Strategic leadership has also been linked to transformational leadership theory. Boal [1] contends that they both predict similar situations but differ in the process and effect on followers. They argue that strategic leadership is concerned with the psychological makeup of leaders and its influence on information and strategic decision making, while transformation leadership involves charisma, intellectual stimulation and inspiration by which leaders cause change in the organization. It can be concluded that they each complement each other. It's actually supposed that charisma is the missing link in strategic leadership [10].

The understanding of strategic leadership is too accentuated by a number of emergent theories. The cognitive complexity perspective that assumes that, once a leader has a high cognitive capacity their ability to receive information, analyze it, interpret it and use it to make decisions is enhanced. Social intelligence perspective facilitates emotional intelligence and discernment in action. It ensures that the values of the organization and interest groups are analogous [1]. The behavioral complexity perspective prompts that when strategic leaders vary their 
behaviors in accordance with the characteristics of people they interact with they are likely to effect change. The above examination depicts strategic leadership as a conglomerate of ideas from different leadership perspectives.

\subsubsection{Conceptualization of Strategic Leadership}

A few scholars have attempted to conceptualize strategic leadership. Strategic leadership is understood as a person's ability to anticipate, envision, maintain flexibility, think strategically and work with others to initiate change that will create a viable future for the organization [2]. Based on this understanding, they conceptualized strategic leadership based on six (6) components; strategic direction, exploiting and maintaining core competences, developing human capital, sustaining an effective organizational culture, enhance practices and establishing organizational control. They are explained below in detail.

One of the major functions of top executives is to define the mission, vision of the organization [11]. They need to ensure that the vision for the future is challenging enough to encourage engagement of employees [1] [12]. The vision should be communicated amply, reasonably articulated, implications and significance for its undertaking spelt out [4]. However, to ensure implementation it's essential that employees are involved in the formulation and determination of the course of action.

Involvement of employees ensures that the organization effectively recognizes and utilizes it's core resources and capabilities. The success of an organization depends on how the leaders make decisions to encourage knowledge sharing and learning through fostering relationships [2]. Effective utilization of the core competencies of an organization yields a competitive advantage.

To effectively utilize core competencies and capabilities, an organization requires the development of human capital. This involves investment in employees with the necessary skills, knowledge and information to be more involved in organizational activities [2]. This improves the absorptive capacity (ability to recognize, assimilate and use knowledge to advance a competitive stance) of the firm [12]. Organizations benefit from employees when they make a decision to invest in their knowledge base and skills.

The ability of an organization to respond to complex changing situations depends on the culture. The onus therefore is on strategic leaders to create a culture that is all embracing [2]. It is claimed that the influence on culture is through the personality of leaders [4]. This has a ripple effect on the performance of the organization. A personality that is focused on achievement, risk and ambiguity tolerant coupled with charisma is able to create a formidable culture that will enhance the position of the firm in the industry.

Sustaining a formidable culture requires presence of strategic controls. These controls ensure that work is done according to the guidelines stipulated [2]. However for these controls to be effective the leaders need to maintain honesty and integrity in all strategic dealings. Many employees would like to work for organizations that exhibit ethical values. More than often these values are embedded in vision and mission statement and the conduct of managers [5]. The creation of an engaged work place is critical to trust and fairness [13]. Once processes in an organization are governed by ethical values of honesty and integrity, a favorable impression is mirrored of its leaders.

Based on the above conceptualization Boal [1] suggested that the essence of strategic leadership lay in leaders being able to develop three (3) capabilities in the organization; absorptive capacity (ability to recognize, assimilate and apply information to new ends), adaptive capacity (capacity to change) and managerial wisdom (discernment and kairos time-ability to make the right timing when making decisions).

A critical glance at these capacities presents some form of correlation between the two conceptualizations. Absorptive capacity recognizes the need to learn and encourages knowledge sharing, development of human capital through training [14]. Adaptive capacity is facilitated by a well articulated vision and structure of the organization [15]. In order to create a culture that is all embracing, leaders need to have managerial wisdom coupled with integrity to enable them make rational and fair judgments [15]. Therefore its essential that managers develop a cognitive ability and effective decision making skills to ensure that all employees in the organization align towards the achievement of organizational goals [16]. Though somehow different combined they create a comprehensive view of strategic leadership and its outcomes for the organization. One of the riding theme, points towards the function of strategic leaders being able to formulate a vision for the organization and ensuring that members work towards its implementation. This compliance can be gained once trust is earned between managers and subordinates. 


\subsubsection{Employee Engagement}

Kahn [6] conceptualized employee engagement as the harnessing of organizational members selves to their work roles; physically, cognitively and emotionally. Kahn [6] prompted that the degree at which people are physically involved, cognitively vigilant and emotionally connected depends on their psychological state. Kahn identified three (3) psychological conditions of meaningfulness, safety and availability. These conditions predict that individuals will be more engaged in meaningful tasks (that grant autonomy, challenge, dignity and worthwhileness). The employees will be engaged in situations where there is freedom of expression without fear of consequence and in situations where they feel more available [17]. This essentially means that the ability of people to engage is depended on their current psychological state.

Meaning in work is what every individual seeks to obtain. This means doing something that someone believes in [5]. Meaningfulness in work is facilitated by personal growth and motivation that is influenced by Job enrichment, work role fit and co-worker relations [18]. It's therefore important for managers to design jobs that offer challenge, opportunities for growth and learning and self expression [5] [6] [18] [19]. It can therefore be understood that once employees get meaning at the work place they will be engaged. The reverse leads to cynicism.

When employees do not trust in the process chances of them being engaged are lean. To engage employees organizations need to resort to relational contracts where commitment and trust is gained overtime [5]. This trust and integrity is the obligation of leadership in an organization. Individuals feel safe when co-worker relations are supportive and trustworthy and open [16] [18] [20]. Hence once organizations provide supportive and conducive environment employees are likely to feel safe and obligated to reciprocate with high levels of engagement.

Without much difference from Kahn [6] and Schaufeli [21] argue engagement as a positive fulfilling work related state of mind characterized by vigor, dedication and absorption. Where vigor is related to Kahn's physical component, dedication relates to emotional component and absorption the cognitive dimension of Kahn's engagement model. They however compare engagement to burnout, claiming that engagement and burnout are antipodes. It can be concluded from their argument that since engagement is a persistent and pervasive, affective cognitive state, then excessive engagement may lead to burnout of an individual. Thus engagement needs to be managed at reasonable levels.

For employees to be engaged they need to be provided with appropriate conditions. Some studies have showed that job resources are positively related to engagement [22] [23]. Resources like social support, leadership, knowledge, autonomy facilitate enhanced engagement. This notion is based on the JD-R model [23] that purports that job demands cause strain when they exceed an employees' adaptive capacity hence should be reduced. Job resources on the other hand promote engagement. Therefore once an employee is facilitated in their work processes it's safe to say they may be engaged.

Availability of resources contributes to a positive work environment. Research shows that when organizations resources; training, autonomy and technology are available then the service climate is enhanced [8]. Thus once employees have a belief in their emotional, physical and cognitive resources, they will be able to engage the self to work [18]. Aside from organizations investing in employees it's essential they managers encourage employees to invest in their own skills and create environments that facilitate the need for balanced participation by employees [24]. When employees are not only motivated but engaged when provided with the necessary resources to perform their work roles and are involved in workplace decision making and implementation.

Organizations therefore have a role to play in influencing employee engagement levels. It's no longer a one way requirement [19]. In retrospect Waldman [19] too argues that individuals tend to be more engaged in activities that offer meaning and purpose. Although it's argued that purpose is created by an individuals, organizations have a role to play in creating environments that foster meaning and purpose or else individuals will become disengaged. Organizations' therefore need to focus on improving teams, wellbeing of individuals, the development of individuals and their ability of give and develop others [19] [24] [25]. It's therefore important to note that employee engagement is limited when employees are not challenged beyond the limit of their competences [26]. If organizations do not fully facilitate an engagement process that contributes to the wellbeing of individuals then little can be expected of performance and productivity.

\subsubsection{Strategic Leadership in Organizations}

The success of an organization is dependent on the decisions its leaders make [2] [4]. Other scholars concluded 
that an organization is a reflection of it top managers [11]. The latter too contend that the experiences, values, abilities, social connection, aspirations and human relations of leaders determine the choice of decisions they make and shape the performance of the organization. Thus the conduct of leaders determines the performance of their followers.

For a strategic leader to be effective it requires that they add charisma to one of their skills [27]. The latter argue that when CEOs adapt charismatic relationships with their subordinates, employee concerns reduce and confidence is generated. Korsgaard [28] too contends that lack of commitment constrains decision implementation. Thus once CEOs adapt charisma as one of their skills with a combination of Justice Principles then they can be able to successfully influence their followers to accomplish their goals.

In a studies carried out by Kontakos [29] and Korsgaad [28], they concluded that individuals trust their leaders if their interests are put into consideration. Leaders therefore need to build and maintain trust within an organization through enhancing their interpersonal and relational competences [30]. It's therefore important that leaders embark on creating trusting relationships with the followers so as to elicit commitment to organizational goals and objectives.

\subsubsection{Strategic Leadership and Employee Engagement}

Trust and integrity in leadership are necessary to create enjoyable relationships. For employees to be engaged it's important that organizations revert to more relational contracts where commitment and trust is created over time [5]. Supervisor and coworker relations are too ranked high in enhancing employee engagement [20] [23]. A study carried by Rothmann [17] among organizations in South Africa concluded that Leadership among other resources facilitated enhanced engagement among employees. It can therefore be assumed that once leaders are supportive of their subordinates', invest in creating trusting relationships and commit to what they pledge to do then, an organization can expect engaged employees.

\section{Methods}

This study took a cross sectional and descriptive research design. The population was 260 in a large Breweries company operating in Uganda. A sample of 155 employees was taken as respondents. The sample was determined using the table provided by Krejcie [31]. The sample of respondents was selected on the basis of gender distribution, marital status, level of education, length of employment and age distribution, all of which are factors one's level of engagement. 147 closed ended usable questionnaires were returned representing a high response rate of $94.8 \%$. In regards to the measurements; Boal [1] measured strategic leadership based on the essence that strategic leadership lay in a leader being able to sustain the following capacities in an organization; capacity to learn, capacity to change and exercising managerial wisdom. A slightly comprehensive view measured strategic leadership based on six components; determining the strategic direction, exploiting and maintaining core competencies, developing human capital, sustaining an effective corporate culture, emphasizing ethical practices and establishing strategic controls [2]. This study therefore measure strategic leadership based on 4 items; strategic direction, capacity to learn, capacity to change and managerial wisdom. All items will be anchored on a 5 point likert scale ranging from 1-no extent to 5-very large extent.

Employee Engagement had a number of well established models for measurement; The Work Engagement Scale (WES) [18] and The JD-R model [23]. For the purpose of this study, the Utrecht Work Engagement Scale (UWES) by Schaufeli [21] was adopted. It was based on 17 items that measure the 3 sub scales of engagement; vigor/physical (6 items)-am bursting with energy every day at work, Dedication/emotional (5 items)-my job inspires me and Absorption/cognitive (6 items)-time flies when am at work and for consistency reasons it was anchored on a 5 point scale ranging from 1-never to 5 always. The instrument was tested for reliability and validity to satisfy their application.

\section{Results and Discussion}

Our respondents were 86 equaling $58.5 \%$ male and 61equivalent $41.5 \%$ female. This was important in this analysis as gender dimension will influence both leadership and employee engagement. Another important demographic aspect was marital status in which (80) $54.4 \%$ were single and the rest (67) were married employees. We also looked at their age distribution in which the majority (75) were found to be relatively young employees 
in the 31 - 40 age group, those above 50 years who can be said to be in the late adult category were relatively few (14) counting at $9.5 \%$ of the respondents. We noted that a small number (15) of employees (10.2\%) had worked for more than 6 years in that organization, depicting that of the total establishment; many had not been engaged with the organization for a long time pointing to serious concerns on leadership among other factors. The respondents were professionals with degree qualifications.

The factor analysis results in the Table 1 were presented to examine the extent to which Strategic Leadership is both applied in Nile Breweries. The factor analysis was preferred in this case because it helped identify the most important dimensions of a study variable and thus gave an indication of the direction that should be pursued when an intervention regarding the variable is to be introduced. On the side of the management of the organization, the factor analysis highlighted the pressing issues that ought to be immediately attended to. In this case, statements which had loadings of less than 0.5 were eliminated to retain the issues that really counted regarding strategic leadership in the organization.

Results indicated that Capacity to Learn, Capacity to Change, Managerial Wisdom and Strategic Direction are some of the major dimensions of the Strategic leadership in the organizations and they explain about $66.165 \%$ of the variable.

Capacity to Learn: Explaining $35.926 \%$ of the strategic Leadership Variable, results indicated that this component is dominantly characterized by issues such as investment in the training of human resources, (0.912), promotion of learning by Line Managers through asking challenging questions which encourage learning (0.881) and their encouragement and building of strong relationships among members (0.846). Overall, it was observed that this component needs to be promoted in the company as it has not yet attained satisfactory levels (Mean = $1.891, \mathrm{SD}=0.408$ ).

Capacity to Change: On the capacity to change dimension, it was noted that the dominating issues of this variable had to do with the capacity of Top Management Team to recognize the needs and goals of each units (0.882), the application of appropriate leadership role for interactions with subordinates, peer and superiors by the line managers (0.866) and the establishment of control systems that facilitate flexible and innovative employee behaviors (0.882).

Managerial Wisdom: This component explains $7.809 \%$ of the study variable and was dominated by the ability of the Line Managers to show compassion in different situations (0.840) and the use of honesty and integrity when making decisions (0.595). This was followed by the Strategic Direction dimension.

Strategic Direction: This component was characterized by how well the Top Management Team determine the vision of the organization (0.513), making very reasonable action plans which are implementable (0.514), and empowering employees to design strategies to achieve the vision (0.895). With a mean of 2.939 and Standard Deviation of 0.724 , it was clear that just like all the other components of the Strategic Leadership variable which had means below 3.00, even the Strategic Direction needs great improvement.

From the above factor analysis results it shows that employees were more affected by the strategic leadership dimension of capacity to learn, compared to the other dimensions of capacity to change, managerial wisdom and strategic direction. This therefore implies that organizational leaders were keener to encouraging and creating an environment of learning and knowledge sharing. Similar studies have shown that resources like training enhance the service climate of the organization [8]. Ireland [2] too consents that the success of an organization lay in leaders making decisions that encourage knowledge sharing and learning. Thus when leaders are supportive of their subordinates and build meaningful relationships then they are susceptible to eliciting cooperation from the employees and thus increase their level of engagement in their work.

The findings too showed that Strategic Leadership was evident in the organization. These are in line with Saks [20] who concluded that the essence of strategic leadership lay in leaders being able to steer an organization towards change, promoting learning in an organization and being able to exercise managerial wisdom with relating with their subordinates and making critical decisions. Strategic direction too as a dimension of strategic leadership is supported by Ireland [2]. It is argued that one of the major functions of top executives is to define the mission and vision of the organization [11]. Other scholars argue that once a vision is established in an organization uncertainty is reduced and the vision also shows opportunity is turned to success [11]. It's also important that leaders communicate the vision to their followers in its broadest sense [27]. This ensures that employees understand the vision and therefore makes it implementation easier. 
Table 1. Factor analysis.

\begin{tabular}{|c|c|c|c|c|}
\hline $\begin{array}{l}\text { Factor Analysis Results: How strategic Leadership Perceptions in the } \\
\text { Company }\end{array}$ & $\begin{array}{l}\text { Capacity to } \\
\text { Learn }\end{array}$ & $\begin{array}{l}\text { Capacity to } \\
\text { Change }\end{array}$ & $\begin{array}{l}\text { Managerial } \\
\text { Wisdom }\end{array}$ & $\begin{array}{l}\text { Strategic } \\
\text { Direction }\end{array}$ \\
\hline The organization invests in training it’s human resources & 0.912 & & & \\
\hline $\begin{array}{l}\text { Line Managers ask } \\
\text { challenging questions that encourage learning }\end{array}$ & 0.881 & & & \\
\hline $\begin{array}{l}\text { Line Managers encourage and build strong relationships among } \\
\text { members }\end{array}$ & 0.846 & & & \\
\hline $\begin{array}{l}\text { Top Management Team develop structures through which knowledge } \\
\text { can be shared }\end{array}$ & 0.795 & & & \\
\hline Employees are encouraged by their Line Managers to work as groups & 0.666 & & & \\
\hline $\begin{array}{l}\text { Top Management Team have the ability to recognize the needs and } \\
\text { goals of each units }\end{array}$ & & .882 & & \\
\hline $\begin{array}{l}\text { The Top Management Team establish control systems that facilitate } \\
\text { flexible and innovative employee behaviors }\end{array}$ & & 0.882 & & \\
\hline $\begin{array}{l}\text { The Line Managers apply appropriate leadership role for interactions } \\
\text { with subordinates, peer and superiors }\end{array}$ & & 0.866 & & \\
\hline $\begin{array}{l}\text { The Top Management Team make sure that employees are } \\
\text { comfortable with constant change }\end{array}$ & & 0.860 & & \\
\hline $\begin{array}{l}\text { Line Managers and employees are committed to treating each other } \\
\text { with respect and dignity }\end{array}$ & & 0.524 & & \\
\hline The Line Managers show compassion in different situations & & & 0.840 & \\
\hline $\begin{array}{l}\text { The Top Management Team apply honesty and integrity when making } \\
\text { decisions }\end{array}$ & & & 0.595 & \\
\hline The Line Managers are economically efficient & & & 0.580 & \\
\hline The Top Management Team have the ability to make timely decisions & & & 0.538 & \\
\hline Employees are empowered to design strategies to achieve the vision & & & & 0.895 \\
\hline The action plans are implementable & & & & 0.514 \\
\hline The Top Management Team determine the vision of the organization & & & & 0.513 \\
\hline Eigen Value & 8.982 & 4.029 & 1.952 & 1.579 \\
\hline Variance \% & 35.926 & 16.115 & 7.809 & 6.315 \\
\hline Cumulative \% & 35.926 & 52.041 & 59.850 & 66.165 \\
\hline Mean & 1.891 & 2.517 & 2.748 & 2.939 \\
\hline SD & 0.408 & 0.676 & 0.992 & 0.724 \\
\hline
\end{tabular}

The Pearson (r) correlation coefficient was employed to test the direction and the degree of association between the study variables (Table 2).

The relationship between strategic leadership and employee engagement

Strategic leadership and employee engagement were significantly and positively correlated $(r=0.63, p<$ 0.01). It was further noted that the components of Strategic Leadership namely Strategic Direction, Capacity to Learn, Capacity to change and Managerial wisdom were all positively related to Employee Engagement ( $\mathrm{p}$ 0.01). These results show that when supervisors and managers are supportive to the subordinates and cooperate to see to it that they help them to acquire skills and knowledge then such employees are more likely to be enthusiastic, arrive early for work and attach more value to their work. Konrad [24] too argues that managers needed to encourage employees to invest in the improvement of their own skills.

Regression Analysis

The regression analysis was conducted in the Table 3 to show the degree to which the Strategic Leadership predicts the Employee Engagement.

From the table above it shows that strategic leadership is a significant predictor of employee engagement at 38.8\% (Adjusted R Square $=0.388$, sig < 0.01). These findings are in line with Rothmann [17] and Saks [20] who concluded in their studies that supervisor and co workers relations enhance employee engagement. These studies confirmed that leadership enhanced engagement among employees. 
Table 2. Pearson correlation coefficient.

\begin{tabular}{|c|c|c|c|c|c|c|c|}
\hline & Mean & $S D$ & 1 & 2 & 3 & 4 & 5 \\
\hline Strategic Direction-1 & 2.939 & 0.724 & 1.000 & & & & \\
\hline Capacity to Learn-2 & 1.891 & 0.408 & $0.508 * *$ & 1.000 & & & \\
\hline Capacity to change-3 & 2.517 & 0.676 & $0.542^{* *}$ & $0.763 * *$ & 1.000 & & \\
\hline Managerial wisdom-4 & 2.748 & 0.992 & $0.497 * *$ & $0.613^{* *}$ & $0.683^{* *}$ & 1.000 & \\
\hline Strategic Leadership-5 & 2.789 & 0.846 & $0.600^{* *}$ & $0.689 * *$ & $0.656^{* *}$ & $0.724 * *$ & 1.000 \\
\hline Employee Engagement & 2.469 & 0.686 & $0.463 * *$ & $0.672 * *$ & $0.634^{* *}$ & $0.520 * *$ & $0.626 * * 1$ \\
\hline
\end{tabular}

**This shows the level of significance of the correlation at the 0.01 level (2-tailed).

Table 3. Regression analysis.

\begin{tabular}{|c|c|c|c|c|c|}
\hline \multirow[b]{2}{*}{ Model } & \multicolumn{2}{|c|}{$\begin{array}{l}\text { Unstandardized } \\
\text { Coefficients }\end{array}$} & \multirow{2}{*}{$\begin{array}{c}\text { Standardized } \\
\text { Coefficients } \\
\text { Beta }\end{array}$} & \multirow[t]{2}{*}{$\mathbf{t}$} & \multirow[t]{2}{*}{ Sig. } \\
\hline & $\mathbf{B}$ & Std. Error & & & \\
\hline (Constant) & 0.526 & 0.321 & & 1.639 & 0.103 \\
\hline Strategic Leadership & 0.808 & 0.083 & 0.626 & 9.673 & 0.000 \\
\hline \multicolumn{6}{|c|}{ Dependent Variable: Employee Engagement } \\
\hline $\mathrm{R}$ & 0.626 & & & & \\
\hline R Square & 0.392 & & & & \\
\hline Adjusted R Square & 0.388 & & & & \\
\hline $\begin{array}{l}\text { Std. Error of the } \\
\text { Estimate }\end{array}$ & 0.616 & & & & \\
\hline F Statistic & 93.558 & & & & \\
\hline Sig. & 0.000 & & & & \\
\hline
\end{tabular}

The model 1 results in the Table 4 show the demographic characteristics of Gender, Marital status, Age group, Tenure, Level of Education, and Rank of position as being significant predictors of employee engagement (sig. 01). Subsequently in model 2 when strategic leadership was introduced it too showed that it was significant predictor of employee engagement. Some scholars argue that the success of an organization depends on the decisions that the leaders make [2] [4]. Therefore for employees to be engaged it's important that leaders embark on creating commitment and trust with their subordinates [5]. Trust and integrity in leadership creates enjoyable relationships which are a prerequisite for engagement.

\section{Conclusion and Managerial Implications}

The study findings showed that there is a positive and significant relationship between the variables of strategic leadership and employee engagement. They indicated that the strategic leadership was a strong predictor of employee engagement with capacity to learn emerging as the most practiced component of strategic leadership at Nile Breweries. This means that the other component of strategic leadership (capacity to change, strategic direction and managerial wisdom) where the least practiced. For an organization to survive and thrive in a competitive and dynamic world it needs to be able to manage change effectively, engage and rally its employees to the overall vision and goal of the organization. It's thus essential for organizations to involve in training of managers and supervisors on strategic leadership skills so that they can effectively be able to interact with their subordinates in a fair manner and encourage consensus towards the objectives and goals of the organization.

It's also important that managers practice charisma with dealing with their subordinates [27]. This way it is assumed that employee concerns will be reduced and confidence in their jobs increased. One of the roles of leaders in an organization is that they rally employee effort towards the achievement of organizational goals and objectives. However this can only be done when the employees trust the actions of leaders in the decision making process. It's therefore paramount that leaders build and maintain trust in the organization by consistently developing their interpersonal and relational skills [30]. 
Table 4. Hierarchical regression analysis.

\begin{tabular}{ccc}
\hline Change statistics & Model-1 & Model-2 \\
\hline (Constant) & $B$ & 1.116 \\
Gender & 3.135 & 0.223 \\
Marital Status & 0.552 & 0.071 \\
Age Group & 0.066 & 0.141 \\
Tenure & 0.117 & 0.306 \\
Highest Level of Education & 0.373 & 0.073 \\
Strategic Leadership & 0.014 & 0.628 \\
& & 0.525 \\
$\mathbf{R}^{2}$ & & 0.501 \\
$\mathbf{R}^{2}$ (Adj.) & Dependent Variable: Employee Engagement & 0.181 \\
$\Delta \mathbf{R}^{2}$ & 0.344 & 52.899 \\
F Change $_{\text {Sig. }}$ & 0.316 & 0.000 \\
\hline
\end{tabular}

\section{Limitations}

Simple random sampling was used to select a representative sample out of the population. There is a possibility that same key respondents would have been left out of the sample size. Additionally the study concentrated more on employees at the operational level of management, so it's possible that some of their views could have been biased regarding their leaders. It was also hard to get empirical evidence of studies carried out specifically relating to the variable under study; strategic leadership and employee engagement, the researcher had to rely on inferences made from studies concerning strategic leadership and employee engagement individually. Therefore more empirical studies are needed to test the relationship between the strategic leadership and employee engagement in different environmental setting. Similarly more studies are needed to test the reliability of the measurement used to measure strategic leadership. The measure used in this study was arrived at after a careful analysis of literature concerning strategic leadership.

\section{References}

[1] Boal, K. and Hooijberg, R. (2001) Strategic Leadership Research; Moving On. Leadership Quarterly, 11, 515-549. http://dx.doi.org/10.1016/S1048-9843(00)00057-6

[2] Ireland, R.D. and Hitt, M.A. (2005) Achieving and Maintaining Strategic Competitiveness in the 21st Century: The Role of Strategic Leadership. Academy of Management Executive, 19, 63-77. http://dx.doi.org/10.5465/AME.2005.19417908

[3] Mathura, V. (2009) The Influence of Strategic Leadership in an Organisation. A Case Study: Ellerine Holdings Limited. Thesis, Rhodes Investec Business School, Rodes University, Grahamstown.

[4] Hogan, R. and Kaiser, R.B. (2005) What We Know about Leadership. Review of General Psychology, 9, 169-180. http://dx.doi.org/10.1037/1089-2680.9.2.169

[5] Cartwright, S. and Holmes, N. (2006) The Meaning of Work: The Challenge of Regaining Employee Engagement and Reducing Cynicism. Human Resource Management Review, 16, 199-208. http://dx.doi.org/10.1016/j.hrmr.2006.03.012

[6] Kahn, W.A. (1990) Psychological Conditions of Personal Engagement and Disengagement at Work. Academy of Management Journal, 33, 692-724. http://dx.doi.org/10.2307/256287

[7] Bakker, A.B. and Schaufeli, W.B. (2008) Editorial Positive Organizational Behavior: Engaged Employees in Flourishing Organizations. Journal of Organisational Behaviour, 29, 147-154. http://dx.doi.org/10.1002/job.515

[8] Salanova, M., Agut, S. and Peiró, J.M. (2005) Linking Organizational Resources and Work Engagement to Employee Performance and Customer Loyalty: The Mediation of Service Climate. The Journal of Applied Psychology, 90, 12171227. http://dx.doi.org/10.1037/0021-9010.90.6.1217

[9] Amanfu, A.A. (2011) Analysis of the Effect of Employee Engagement on the Performance of an Organisation. A Case Study of Guinness Ghana Breweries Ltd. Maastricht School of Management. 
[10] Cannella Jr., A.A. and Monroe, M.J. (1997) Contrasting Perspectives on Strategic Leaders; Toward a More Realistic View of Top Managers. Journal of Management, 23, 213-137. http://dx.doi.org/10.1177/014920639702300302

[11] Finkelstein, S., Hambrick, D.C. and Cannella, A.A. (2009) Strategic Leadership; Theory and Research on Executives, Top Management Teams and Boards. Oxford University Press, Oxford, 1-451.

[12] Serfontein, K. and Hough, J. (2011) Nature of the Relationship between Strategic Leadership, Operational Strategy and Organisational Performance. South African Journal of Economic and Management Sciences, 14, 393-406.

[13] Macey, W.H. and Schneider, B. (2008) The Meaning of Employee Engagement. Industrial and Organizational Psychology, 1, 3-30. http://dx.doi.org/10.1111/j.1754-9434.2007.0002.x

[14] Cohen, W.M. and Levinthal, D.A. (1990) Absorptive Capacity: A New Perspective on Learning and Innovation. Administrative Science Quarterly, 35, 128-152. http://dx.doi.org/10.2307/2393553

[15] Phipps, K.A. and Burbach, M.E. (2010) Strategic Leadership in the Nonprofit Sector: Opportunities for Research. Journal of Behavioral and Applied Management, 11, 137-154.

[16] Bagire, V. and Namada, J. (2013) Managerial Skills, Financial Capability and Strategic Planning in Organizations. American Journal of Industrial and Business Management, 3, 480-487. http://dx.doi.org/10.4236/ajibm.2013.35055

[17] Rothmann, S. and Rothmann Jr., S. (2010) Factors Associated with Employee Engagement in South Africa. SA Journal of Industrial Psychology, 36, 1-12. http://dx.doi.org/10.4102/sajip.v36i2.925

[18] May, D.R., Gilson, R.L. and Harter, L.M. (2004) The Psychological Conditions of Meaningfulness, Safety and Availability and the Engagement of the Human Spirit at Work. Journal of Occupational and Organisational Psychology, 77, 11-37. http://dx.doi.org/10.1348/096317904322915892

[19] Shuck, B. and Rose, K. (2013) Reframing Employee Engagement within the Context of Meaning and Purpose: Implications for HRD. Advances in Developing Human Resources, 15, 341-355. http://dx.doi.org/10.1177/1523422313503235

[20] Saks, A.M. (2006) Antecedents and Consequences of Employee Engagement. Journal of Managerial Psychology, 21, 600-619. http://dx.doi.org/10.1108/02683940610690169

[21] Schaufeli, W.B. and Salanova, M. (2002) The Measurement of Engagement and Burnout: A Two Sample Confirmatory Factor Analytic Approach. Journal of Happiness Studies, 3, 71-92. http://dx.doi.org/10.1023/A:1015630930326

[22] Nahrgang, J.D., Morgeson, F.P. and Hofmann, D. (2011) Safety at Work: A Meta-Analytic Investigation of the Link between Job Demands, Job Resources, Burnout, Engagement, and Safety Outcomes. The Journal of Applied Psychology, 96, 71-94. http://dx.doi.org/10.1037/a0021484

[23] Rothmann, S., Mostert, K. and Strydom, M. (2006) A Psychometric Evaluation of the Job Demands-Resources Scale in South Africa. SA Journal of Industrial Psychology, 32, 76-86. http://dx.doi.org/10.4102/sajip.v32i4.239

[24] Konrad, B.A.M. (2006) Engaging Employees through High-Involvement Work Practices. Ivey Business Journal, Online.

[25] Robertson, I.T. and Cooper, C.L. (2010) Full Engagement: The Integration of Employee Engagement and Psychological Well-Being. Leadership \& Organization Development Journal, 31, 324-336. http://dx.doi.org/10.1108/01437731011043348

[26] Meyer, J.P. and Gagné, M. (2008) Employee Engagement from a Self-Determination Theory Perspective. Industrial and Organizational Psychology, 1, 60-62. http://dx.doi.org/10.1111/j.1754-9434.2007.00010.x

[27] Waldman, D., Javidan, M. and Varella, P. (2004) Charismatic Leadership at the Strategic Level: A New Application of Upper Echelons Theory. The Leadership Quarterly, 15, 355-380. http://dx.doi.org/10.1016/j.leaqua.2004.02.013

[28] Korsgaard, M.A., Schweiger, D.M. and Sapienza, H.J. (1995) Building Commitment, Attachment, and Trust in Strategic Decision Making Teams: The Role of Procedural Justice. Academy of Management Journal, 38, 60-84. http://dx.doi.org/10.2307/256728

[29] Kontakos, A.-M. (2006) Employee Engagement and Fairness in the Workplace. 18-32.

[30] Hitt, M.A. and Ireland, R.D. (2002) The Essence of Strategic Leadership: Managing Human and Social Capital. Journal of Leadership and Organisational Studies, 9, 3-14. http://dx.doi.org/10.1177/107179190200900101

[31] Krejcie, R.V. and Morgan, D.W. (1970) Determining Sample Size for Research Activities. The NEA Research Bulletin, 38, 607-610. 
Submit or recommend next manuscript to OALib Journal and we will provide best service for you:

- Publication frequency: Monthly

- 9 subject areas of science, technology and medicine

- Fair and rigorous peer-review system

- Fast publication process

- Article promotion in various social networking sites (LinkedIn, Facebook, Twitter, etc.)

- Maximum dissemination of your research work

Submit Your Paper Online: Click Here to Submit

Contact Us: service@oalib.com 